\title{
La cuestión funeraria islámica: el "enquistado" caso de la metrópolis madrileña
}

\section{The Islamic burial question: the "frozen" case of the Madrid metropolis}

Óscar SALGUERO MONTAÑO

Universidad Complutense de Madrid

oscarsal@ucm.es

https://orcid.org/0000-0001-5289-1472

Alba SIGUERO LIZANO

Universidad Complutense de Madrid

asiguero@ucm.es

https://orcid.org/0000-0001-5709-611X

Recibido 22/06/2021. Aceptado 28/09/2021

Para citar este artículo: Óscar SALGUERO y Alba SIGUERO (2021): "La cuestión funeraria islámica: el "enquistado caso de la metrópolis madrileña" en Revista de Estudios Internacionales Mediterráneos, 31, pp. 108-127.

Para acceder a este artículo: https://doi.org/10.15366/reim2021.31.006

\section{Resumen}

La pandemia del covid-19 ha vuelto a situar en la palestra pública las carencias en materia de enterramiento y servicios funerarios que tienen los y las musulmanas en España, especialmente en grandes urbes como Madrid, que siguen sin contar con un espacio funerario acorde con sus prescripciones religiosas, tal y como garantiza el derecho fundamental de libertad religiosa y de culto. Para abordar esta problemática, en el presente artículo se analizan las reivindicaciones realizadas por las comunidades musulmanas en el marco de los derechos de ciudadanía y el derecho a la ciudad, atendiendo principalmente a las prácticas y discursos de los distintos actores implicados.

Palabras clave: islam, cementerios islámicos, gestión pública, derecho a la ciudad, Madrid 


\section{Abstract}

The covid-19 pandemic has put the deficiencies related to burial and funeral services for Muslims in Spain back into the public arena, especially in large cities such as Madrid, which still do not have a burial space in accordance with Islamic religious requirements, as guaranteed by the fundamental right to freedom of religion and worship. To address this problem, this article analyzes the claims made by Muslim communities in the framework of citizenship rights and the rights to the city, focusing on the practices and discourses of the different actors involved.

Keywords: Islam, Islamic cemeteries, public management, right to the city, Madrid

\section{Introducción}

La cuestión funeraria islámica, es decir, todo lo relativo a los procesos de consecución de un espacio donde enterrar a los difuntos musulmanes, así como el tratamiento previo del cuerpo y el propio desarrollo del sepelio de modo acorde con las prescripciones religiosas del islam (purificación del cuerpo, inhumación en contacto con la tierra u orientación de la tumba hacia Meca), es una de las principales preocupaciones de las comunidades musulmanas en Europa occidental (Maussen, 2007: 11). Relativa a la misma se plantean cuestiones diversas como la concepción de los espacios funerarios como una herramienta de integración y construcción de las identidades musulmanas en Gran Bretaña (Shaw, 2004: 279; Ansari, 2007: 547); la concesión de derechos públicos a las organizaciones musulmanas en Alemania y Austria (Klapetek, 2017: 3); los problemas planteados a los musulmanes por la normativa de las autoridades en los llamados "cementerios laicos" de Francia (Ural, 2014: 1); o la financiación vía impuestos de la materialización del derecho a enterrar a sus muertos según sus propias tradiciones en Dinamarca (Klausen, 2007: 8). En el caso español se trata también de una de las demandas más reiteradas por las comunidades a las instituciones públicas de distinta jurisdicción territorial, durante al menos las tres últimas décadas (Moreras, 2004: 429; Tarrés, 2006: 431; Salguero, 2011: 223; 2013: 202; Astor y Griera, 2016: 255; Tarrés y Moreras, 2019 : 194; Lems, 2021: 27).

En este marco, algunas de las reivindicaciones específicas más recurrentes van desde la modificación de la normativa funeraria para permitir el enterramiento sin féretro, hasta la rehabilitación de los cementerios musulmanes construidos durante la Guerra Civil, pasando por la construcción o habilitación de una nueva parcela en municipios enclavados en áreas geográficas donde pese al volumen de población musulmana existente, no cuentan con un cementerio. Esta última reivindicación proyecta en la esfera pública una carencia generalizada de espacios de enterramientos que respondan a las necesidades de la ciudadanía musulmana española. Una carencia que se hace especialmente significativa en territorios como Madrid, pese a su notable volumen de población musulmana en la Comunidad estimado en casi trescientas mil personas censadas (Observatorio Andalusí, 2020: 7), y que se ha visto agudizada durante la actual pandemia del covid-19 y el fallecimiento de hombres y mujeres de esta adscripción, entre ellos el anterior presidente de la Comisión Islámica de España (CIE) y de la federación Unión de Comunidades Islámicas de España (UCIDE), Riay Tatary. 
La cuestión funeraria islámica se constituye de esta manera como un eje que articula parte de la acción política y social de la ciudadanía musulmana y de sus comunidades religiosas y también civiles; es, por tanto, un derecho de ciudadanía, un "derecho a la ciudad" (Lefebvre, 1968). En sus procesos de reivindicación salen a la palestra pública un complejo entramado de actores públicos y privados, religiosos y civiles, interrelacionándose elementos religiosos, civiles, morales, políticos y jurídicos, que implican un acercamiento holístico que contemple todas sus implicaciones, en tanto "hecho social total" (Mauss, 1979).

El caso de la metrópolis madrileña -sin cementerio islámico por el momento y cercano al del municipio de Griñón, que, como veremos, no ha estado exento de polémica- sirve para ejemplificar este proceso colectivo que lleva incidiendo con mayor o menor intensidad en la cuestión funeraria islámica local desde hace ya tres décadas, coincidiendo con el asentamiento de la población musulmana que llegaría como migrante, y que hoy, pese a ser ya ciudadana de pleno derecho, tiene que sortear una serie de dificultades para ser enterrada según su tradición religiosa. Un proceso de reivindicación que en el caso de Madrid se ha visto intensificado en los últimos años por colectivos islámicos, tanto religiosos como seculares, al hilo de circunstancias diversas como los cambios en la política local (del Ahora Madrid de Carmena, al Partido Popular de Almeida) o la pandemia del covid19.

A partir de ello, el presente artículo pretende describir el complejo y dilatado proceso de reivindicación de un cementerio islámico en la ciudad de Madrid, atendiendo especialmente a las prácticas y discursos de los distintos actores relacionados. Con carácter específico, este artículo también quiere contextualizar de forma general, a través del caso de la metrópolis madrileña, las reivindicaciones funerarias de la población y comunidades musulmanas, en términos de derechos de ciudadanía como el reconocimiento de la diferencia y la inclusión; es decir, como un derecho a la ciudad: derecho al acceso y uso del espacio público que constituyen los cementerios municipales.

Para responder a estas pretensiones, un primer apartado dará cuenta de las principales cuestiones metodológicas que han precedido esta redacción, incidiendo especialmente en la reconstrucción del estudio de caso a partir de los diferentes relatos de diversos actores. Tras ello, se desarrollarán los tres ejes del armazón teórico: el concepto de hecho social total que permite explicar la multidimensionalidad de la cuestión funeraria islámica en el Estado español; su relación con los derechos de ciudadanía; y más especialmente su concepción como un derecho a la ciudad. A continuación, a partir de una contextualización sociohistórica de la demanda en España, se analizará el caso de la metrópolis madrileña y sus implicaciones para la generalidad de la cuestión. Por último, se plantearán una serie de conclusiones que reflexionan acerca de las cuestiones planteadas.

\section{Apuntes metodológicos}

Este texto parte de los horizontes investigativos resultantes de un estudio anterior de mayores dimensiones en torno a las manifestaciones religiosas en el espacio público de diferentes confesiones en las ciudades de Madrid y Barcelona ${ }^{1}$. En el estudio del caso del islam madrileño, el espacio público se presentó en los comienzos de esta investigación enmarcado en la generalidad de la cuestión espacial, en la que las necesidades funerarias estuvieron muy presentes en la práctica

\footnotetext{
${ }^{1}$ Proyecto CSO2015-66198-P «Expresiones Religiosas en el Espacio Urbano en Madrid y Barcelona (EREU - MyB)», Dirección General de Investigación Científica y Técnica y Subdirección General de Proyectos de Investigación del Ministerio de Economía y Competitividad, I+D+i Excelencia, convocatoria 2015.
} 
totalidad de las entrevistas realizadas, generándose un volumen de materiales merecedores de analizar en posteriores trabajos como el presente. Junto a estas primeras entrevistas, entre las cuales se cuenta una con la $\mathrm{CIE}$, recientemente se han realizado otras que van desde una persona que ha enterrado a un familiar en el cementerio de Griñón durante la pandemia, hasta "nuevos" actores que han venido surgiendo con el relanzamiento público de la problemática al hilo del covid19, así como de aquellos otros de los que hemos ido teniendo constancia a través de un trabajo diacrónico que ha permitido trazar una genealogía de nombres y grupos que han participado en las sucesivas negociaciones y reivindicaciones por contar en la capital madrileña con un espacio funerario islámico.

Para ello, además de la selección y análisis de bibliografía en torno a los enterramientos islámicos que ha conformado el estado de la cuestión, se han consultado distintos tipos de fuentes, como la normativa afectada y los distintos acuerdos y convenios suscritos con el ente público, informes sociodemográficos y de otra índole elaborados por diversos actores en juego (comunidades islámicas, asociaciones y otros) y las sesiones plenarias locales de distintos momentos en las que la cuestión funeraria islámica ha sido tratada.

Por último, la situación generada por la pandemia del covid-19 no sólo supuso el detonante para embarcarse en este "nuevo" trabajo, sino que también ha incidido en la readaptación metodológica de la investigación, dotando a la exploración en Internet de gran protagonismo. Así, con carácter complementario, y en aras de esa visión diacrónica, se ha consultado profusamente un gran volumen de prensa online a nivel estatal, que además de ofrecer una impronta de la actual situación en diferentes puntos de la geografía, también ha posibilitado reconstruir parcialmente la historia local de los sucesivos intentos por contar en Madrid con un cementerio musulmán.

\section{La cuestión funeraria como hecho social total}

El ensayo sobre los dones de Marcel Mauss refiere los "hechos sociales totales" como actos de tipo institucional, en los que, como el potlatch o kula, "se expresan a la vez y de golpe todo tipo de instituciones: las religiosas, jurídicas, morales" (Mauss, 1979: 157), y como "hechos que ponen en juego a la totalidad de la sociedad y sus instituciones" o a "un vasto número" de ellas (Mauss, 1979: 259). A partir de esta definición, los enterramientos pueden interpretarse como hechos sociales totales en cuanto que, como acciones humanas con proyección colectiva, acogen un conjunto de prácticas -religiosas, morales, jurídicas, institucionales, políticas...- de carácter amplio que invitan a una aproximación holística a los mismos, es decir, más que de enterramientos, habría que hablar de "cuestión funeraria" pues, en la misma, vienen implícitas muchas más cuestiones estructurales.

El caso de los enterramientos islámicos en España responde a estos parámetros, al que podemos aproximarnos desde cualquiera de estos ámbitos de forma interrelacionada. Desde una perspectiva religiosa, el sentido de todo el sepelio es eminentemente religioso, el cual ha de responder a unas prescripciones confesionales concretas; así como también lo son muchos de los significados que van aparejados a las reivindicaciones que exigen el cumplimiento de unos "derechos religiosos" previamente reconocidos (Lems, 2021: 146-239). En lo relativo a la moral, familiares, allegados y 
comunidad cercana se convierten en garantes de las últimas voluntades, de su tratamiento adecuado y de preservar su memoria (Moreras, 2004: 427); unas cuestiones que durante la pandemia han podido verse incididas notablemente. Como señalaba una vecina musulmana de San Martín de Valdeiglesias que había enterrado recientemente a su abuela:

Te choca un poco, sobre todo, el hecho de no poder despedirte, te cuestionas un poco: el ataúd estaba cerrado, no podías ver si era ella. Te queda entonces un poco con el "no me he despedido", como que te autoengañas un poco del duelo y que tu mente te juega una mala pasada, te cuestionas. (...) Sí que se hizo un pequeño rezo de pie, nada, creo que dos minutos o así el imam y las cuatro personas que había. Ahí mismo en el cementerio, la sacaron del coche fúnebre y ahí mismo (Tiziri, San Martín de Valdeiglesias, 5/05/2021).

Del mismo modo, la propia performance del ritual también se ha visto incidida por el cumplimiento de las medidas de salud pública. Como explicaba esta vecina:

Al ser muerte por covid no la llevan ni a la [mezquita de la] M30; no pasa por el típico lavado que hacemos los musulmanes a nuestros difuntos. De ahí al tanatorio, y del tanatorio se la llevaron al día siguiente al cementerio de Griñón. (...) En principio solo pueden ir hombres a enterrar, pero claro... al no tener casi familiares y nosotros con covid y confinados pues... Mi hermana sí que fue, pero no participó activamente. Ahí estaban tres personas, que creo que trabajan en el cementerio de Griñón, más el imam que está allí en la pequeña mezquita, y mi cuñado, cinco personas (Tiziri, San Martín de Valdeiglesias, 5/05/2021).

En el ámbito político se enmarcan los requerimientos a los poderes públicos para el efectivo cumplimiento de la legislación por parte de las comunidades, o para la modificación de normativas que, en el nivel autonómico, impiden en algunos territorios el enterramiento sin féretro. Incluso desde el ámbito económico es analizable la cuestión funeraria. Por un lado, la carencia de cementerios cercanos implica generalmente costear el transporte del difunto a otra Comunidad Autónoma que permita su enterramiento, o como sucedía especialmente hace unos años a la repatriación del cadáver a su país de origen, si es el caso, a través de colectas comunitarias o mediante el cobro de seguros de defunción específicos para personas migrantes (Tarrés y Salguero, 2010: 345; Moreras, 2004: 427-428). Por otro lado, como se examinará más adelante, intereses económicos de entidades públicas y privadas pueden convertirse en obstáculos para las comunidades musulmanas a la hora de reclamar derechos relativos a la cuestión funeraria.

Junto a todos estos ámbitos también se debe tomar en consideración el jurídico, incluyendo en él tanto la legislación que reconoce el derecho de las personas musulmanas a recibir un enterramiento de acuerdo con sus rituales funerarios, como el reconocimiento de la CIE como interlocutor oficial ante las instituciones públicas. Este último hecho marcará significativamente el curso de las reivindicaciones realizadas por las comunidades musulmanas ante las instituciones públicas, debido a que mientras en esta, a diferencia de la católica, no se reconoce una jefatura suprema religiosa que la represente, a la hora de dirigirse a las instituciones públicas será la CIE quien asuma esta función por reconocimiento público.

Por último, la gestión pública de los enterramientos islámicos en España y la exigencia del cumplimiento de la legislación vigente han interpelado, por un lado, a una serie de actores públicos competencialmente relacionados con la gestión pública de los enterramientos islámicos en España, desde los propios ayuntamientos, encargados de la gestión de los cementerios de titularidad pública, hasta el Gobierno central con quien se firmaría en 1992 el Acuerdo de Cooperación que contempla en su artículo 2 el derecho de enterramiento islámico, pasando por los poderes autonómicos, depositarios de la competencia legislativa en materia de policía mortuoria. Y, por otro 
lado, la reivindicación del cumplimiento de la legislación vigente ha sido efectuada tanto por las entidades y federaciones religiosas musulmanas, como por agrupaciones seculares, ciudadanas y civiles, en fechas más recientes.

En este sentido una de las principales implicaciones del hecho social total es que lo social deviene real solo cuando se desenvuelve como sistema, entre cuyas partes pueden descubrirse conexiones, equivalencias y solidaridades (Lévi-Strauss, 1979: 29). El acto del enterramiento trae así consigo muchas otras cuestiones que dan cuenta de una estructura más general, "implicada en el carácter relacional del pensamiento simbólico" (Cazeneuve, 1970: 130) y determinada, en este caso, por la discriminación del heterogéneo colectivo social islámico, gestándose en él tales conexiones, equivalencias y solidaridades por la consecución de un fin común, en este caso, el acceso legítimo y con garantías al enterramiento islámico para toda la población musulmana del Estado español.

A partir de las distintas implicaciones expuestas que plantea la cuestión funeraria islámica, a continuación, nos detendremos en las relacionadas de forma directa con los procesos de reivindicación de espacios funerarios y su imbricación con las luchas identitarias y por la ciudadanía, si bien las menciones interrelacionadas a otros ámbitos estructurales serán más que recurrentes.

\section{La cuestión funeraria islámica en el marco de los derechos de ciudadanía}

La construcción de una "ciudadanía religiosa" basada fundamentalmente en la legalización de las creencias (Vaggione, 2017) implica la necesaria reconstitución de los marcos normativos de los Estados -ahora multiculturales, y también plurireligiosos- y de la propia institución de la ciudadanía, de acuerdo con principios pluriconfesionales, además de seculares (Hudson, 2003). Ello supone concebir la ciudadanía religiosa como la defensa de una serie de derechos relacionados con el ejercicio de sus creencias y prácticas religiosas y su encaje en los ordenamientos legales correspondientes, caso de los intentos por incidir en los sistemas normativos nacionales e internacionales, o sobre el propio cumplimiento de estos.

Para Klausen (2007), la cuestión del islam en Europa occidental plantea, entre otras cuestiones, la relativa a su papel en la vida pública y a las formas de construir instituciones que permitan a los y las musulmanas europeas practicar su religión de forma compatible con los marcos jurídicos y sociales. En el caso español, la CIE fue nombrada por el Gobierno central interlocutor oficial de los musulmanes para firmar en 1992 los Acuerdos de Cooperación con el Gobierno, siendo desde entonces la estructura encargada de gestionar una situación de generalizada carencia de cementerios islámicos en la geografía estatal.

Las personas, por su parte, conciben la ciudadanía religiosa integrada en el marco de un concepto más amplio y con "múltiples capas" caracterizado por la pertenencia simultánea a varias comunidades políticas (Yuval-Davis, 2006). En este orden, los derechos reivindicados van desde la pertenencia plena a una comunidad política y respetados en su singularidad, en este caso, su "musulmanidad" (reconocimiento de la diferencia), hasta su participación activa en la misma (derecho a la inclusión). Sin embargo, los y las creyentes además han de responder a una serie de "exigencias" sociales relacionadas con la modernidad de las confesiones, y, en el caso del islam, también con la transparencia (Salguero, 2020: 185), la no violencia (Téllez, 2018: 23-25) o la igualdad 
sexogenérica (Fernández, 2018: 75-76), pues la "nueva presencia" musulmana ha sido tomada por las sociedades europeas multiculturales como "ejemplo y también como límite para extender el principio de reconocimiento" (Moreras, 2017: 16). En este sentido, parece que la cuestión relevante ya no debería ser si los gobiernos se acomodan a las demandas de reconocimiento de los musulmanes, sino qué demandas se acomodan, de qué manera y por qué razones, tal y como sostiene un análisis comparativo entre Francia y Holanda de las adaptaciones institucionales hacia los musulmanes en el ámbito funerario y la construcción de mezquitas (Van den Breemer y Maussen, 2012: 279).

Estas reivindicaciones giran en torno a la lucha contra la discriminación y al cumplimiento efectivo de ciertos derechos religiosos islámicos, que deja de ser competencia exclusiva de las estructuras oficiales religiosas como la CIE, y pasa a ser otro motivo más para la participación activa de organizaciones laicas y colectivos no formales, que no se han estructurado como comunidades religiosas, sino civiles y ciudadanas en contra de la discriminación social, política, religiosa, económica, racial, de género, etc. Estas nuevas "subjetividades políticas" musulmanas son una posición desde la que reclamar derechos (Krause y Schramm, 2011: 128) y muestran cómo se negocia el acceso a los recursos, cómo se construyen las redes de pertenencia y quiénes otorgan o no el reconocimiento de estas nuevas subjetividades (Lems, 2021: 64). Junto a las luchas contra la discriminación islamófoba, en sus agendas están también presentes el cumplimiento de los derechos religiosos, consiguiéndose en algunos municipios "algún avance puntual respecto a los cementerios islámicos" (Lems, 2021: 188-189).

\section{La cuestión funeraria islámica y el derecho a la ciudad}

Los derechos de ciudadanía son, a su vez, derechos eminentemente urbanos, derechos de ciudad, pues "el ciudadano se hace haciendo su ciudad; no es objeto de pertenencia de la cosa-ciudad, sino que pertenece a un sistema de acciones del que él mismo es fuente"; y es en los espacios públicos donde este derecho, no simplemente se reconoce, sino que se ejercita (Thiebaut, 1998: 24-25). Además, cuando la ciudad es un espacio que hay que conseguir acceder en términos de igualdad con el resto de la sociedad es también un "derecho a la ciudad". Henri Lefebvre concibió el derecho a la ciudad (1968) como la recuperación por la sociedad del espacio urbano que le había sido negado o restringido. Se trataba de recuperar aquellos espacios cuyos sentidos eran dotados por la práctica colectiva de la ciudadanía, en definitiva, el espacio público, o su equivalente teórico de "espacio urbano", un "espacio de y para lo urbano, entendido como una forma específica de organizar y pensar el tiempo y el espacio en general, y no sólo en el marco físico de ese constructo material que es la urbe" (Delgado, 2013: 3). El espacio público es, por tanto, algo más que calles, plazas y parques, es "todo aquello que no es propiedad privada", de libre e igual acceso independientemente de la posición social ostentada (Aramburu, 2008: 144).

El ámbito espacial ha sido siempre objeto de interés y preocupación, instando a los poderes públicos al reconocimiento y protección legal de los lugares de culto y de otros espacios considerados "religiosos", como desarrollo de un derecho de libertad religiosa y de culto de más amplias dimensiones. Con carácter más reciente, el libre acceso al espacio público y su visibilización en el mismo, participando de él, es otra de las demandas espaciales más recurrentes, tanto por la muchas veces limitada capacidad de las mezquitas y oratorios que parece seguir obedeciendo a cierta precariedad endémica de recursos (Alonso et al, 2010: 171), como por la necesidad de proyectarse públicamente en la esfera pública (Salguero y Hejazi, 2020). Entre los citados espacios religiosos, y también públicos, los cementerios desempeñan un importante papel: contar con un espacio funerario islámico sigue estando entre las máximas prioridades, no solo de las comunidades religiosas, sino, como veremos, de todo un espectro mayor de organizaciones. Es la reivindicación 
del cumplimiento de la norma, "usar" un espacio social y público que pese a estar reconocido, les está restringido, negado; o en su materialización más literal puede ser también recuperar el espacio perdido de esos cementerios islámicos que, como el de Griñón (Madrid), fueron construidos durante la Guerra Civil para los caídos de las tropas musulmanas del bando golpista.

La cuestión espacial, y más especialmente la funeraria, se conforma de esta manera como un elemento clave a integrar en los derechos de ciudadanía, en el derecho a la ciudad, el cual se hace carne en la experiencia política colectiva, acometida desde distintos frentes y por diversos actores, religiosos, y también civiles. Mientras el mundo se urbaniza, las sociedades se disgregan, y el acceso al espacio adquiere connotaciones de primer orden. El espacio funerario islámico en países occidentales como España -reconocido, pero no efectivo- se conforma, siguiendo la terminología de Lefebvre (1974), por un lado, como "espacio percibido", el de la experiencia material de los musulmanes y musulmanas, que vinculan realidad cotidiana (uso del tiempo) y espacio urbano (uso del espacio), englobando producción y reproducción social; y, por otro lado, como espacio "vivido", el de creyentes y correligionarios, donde se profundiza en la búsqueda de nuevas posibilidades de la realidad espacial. Es, en suma, el espacio de lo imaginario y lo simbólico dentro de una existencia material.

\section{Contextualización de la actual cuestión funeraria islámica en el Estado español}

La necesidad de espacios funerarios islámicos en el Estado español se hizo más acuciante con el inicio de la pandemia del covid-19 y el aumento del número de fallecimientos; una necesidad agravada que saldría a la luz pública con especial intensidad con el fallecimiento del presidente de la CIE y de la UCIDE, Riay Tatary, el 6 de abril de 2020, tras dos semanas ingresado en el hospital madrileño de La Paz. Unos días después, se publicaba el Informe sobre los cementerios para los musulmanes, a fecha de 10 de abril de 2020 elaborado por Mohamed Ajana Elouafi, secretario de la $\mathrm{CIE}$, en el que se calificaba la cuestión funeraria islámica en España como "sensible, delicada y emocionalmente relevante para los vecinos de confesión musulmana en territorio español"; y añadía que, si bien, es una "realidad que se venía arrastrando desde hace casi treinta años se ve agravada actualmente por la pandemia del covid-19" (Ajana, 2020: 2). De este informe se extrae que en abril de 2020 existían un total de 35 cementerios islámicos, cuya implantación geográfica era desigual, con todavía cinco Comunidades Autónomas que carecían de parcelas para entierros musulmanes, ni de cementerios privados para ello: Asturias, Cantabria, Castilla - La Mancha, Extremadura y Galicia, lo cual genera una necesidad de desplazamiento del difunto y sus allegados, que se complica cuando, "en muchos casos, los cementerios sólo permiten el enterramiento de personas que residen en su propia provincia". Además, a la fecha de publicación del informe, no todos estos cementerios estaban en activo: los de Lucena (Córdoba) y Huelva se encontraban en proceso de acondicionamiento; y los de Córdoba, Murcia y Palma de Mallorca estaban ya colmatados. Es decir, un total de 30 espacios funerarios islámicos para una población estimada en dos millones de personas, según sus propias fuentes del Observatorio Andalusí (Ajana, 2020: 3). 
En el mismo documento, la CIE valoraba "muy positivamente los pasos dados" en el abordaje normativo de la cuestión por los entes públicos autonómicos como Galicia, que en julio de 2019 había modificado el artículo 21 de su decreto de sanidad mortuoria para posibilitar el enterramiento sin féretro (siguiendo el ejemplo de otros entes autonómicos como Andalucía, Valencia, Ceuta o Melilla); y Extremadura, en donde también en julio de 2019, a través del imam de la mezquita de Badajoz y delegado de la CIE en Extremadura, Adel Najjar, se firmaba un protocolo para el enterramiento islámico entre la Junta de Extremadura y la filial de la UCIDE en Extremadura.

Efectivamente algunas instituciones han comenzado a dar algunos pasos, especialmente ante la emergencia sanitaria del covid-19. En la Región de Murcia, el Ayuntamiento de la capital culminaba en enero de 2021 el acondicionamiento del cementerio municipal con la construcción de 69 nuevas fosas. En Cataluña, el Ayuntamiento de Lleida anunciaba en abril de 2020, su intención de habilitar "un espacio en el cementerio municipal a la comunidad islámica por si hiciera falta realizar un entierro en este periodo de crisis por el coronavirus" ${ }^{2}$. Siete meses después se hacía público el acuerdo adoptado por la Unión de Comunidades Islámicas de Cataluña (UCICAT), la Federación del Consejo Islámico de Cataluña (FCIC) y la Federación Islámica de Cataluña (FIC) con varios ayuntamientos y la Generalitat de Catalunya, que se materializaría, entre otras cuestiones, en la habilitación para el siguiente año de una parcela "con 63 sepulturas" en el cementerio de Roques Blanques ubicado en El Papiol (Barcelona). En la Comunidad Autónoma Vasca, por su parte, destaca el caso de Arrigorriaga (Vizcaya), cuyo Ayuntamiento anunciaba en julio de 2020 la habilitación de "16 nichos reservados al entierro de personas de la comunidad musulmana" tras la alerta de la dirección de Víctimas y Derechos Humanos del Gobierno vasco "ante la problemática generada para este colectivo en la Comunidad Autónoma Vasca con motivo de la emergencia sanitaria por el covid$19^{\prime \prime 3}$. En diciembre del mismo año el Gobierno local de Vitoria-Gasteiz anunciaba también la habilitación de una parcela funeraria islámica en el cementerio municipal de El Salvador. En la Comunidad de Madrid, el Ayuntamiento de Griñón decidía en abril del 2020 construir cien tumbas más en el cementerio musulmán de la localidad que, debido al incremento de decesos en el primer trimestre del año, había cubierto ya el cupo de enterramientos previstos para todo el año. La decisión se tomó unos días después del enterramiento de Riay Tatary en ese mismo cementerio.

...si te mueres por covid vas directamente a Griñón y no hay forma. Cuando enterramos a mi abuela, era la número 27 de su fila, y había bastante terreno, pero es que ahora, estuvimos el domingo pasado, y después de mi abuela hay tres filas más y hay espacio para otras tres como mucho, mucho; y en cada fila hay espacio creo como para 34 tumbas (Tiziri, San Martín de Valdeiglesias, 5/05/2021).

Sin embargo, la situación generalizada dista de estas actuaciones que podrían calificarse como "buenas prácticas"; la realidad actual en muchos otros territorios es más bien distinta, como muestran los datos aportados por la $\mathrm{CIE}$ y el significativo aumento del número de reivindicaciones desde que se inició la pandemia, las cuales, como veremos, no están únicamente protagonizadas por la CIE, sino también, y cada vez más, por un variado conjunto de organizaciones tanto religiosas, como civiles, ajenas muchas de ellas a la órbita de influencia del interlocutor oficial, la CIE. Al hilo del caso citado de Extremadura, el mismo Adel Najjar que conseguía la firma del protocolo con el Gobierno regional, se lamentaba públicamente en febrero de 2021 por la negativa del alcalde de

\footnotetext{
2 Véase: Redacción (2020): “El Ayuntamiento de Lleida ofrece un terreno para un cementerio musulmán”, 10/04/2020. mundoislam.com. Recuperado de: https://mundoislam.com/actualidad/espana/2020/04/10/ayuntamiento-Ileidaofrece-terreno-cementerio-musulman/

${ }^{3}$ Véase: Laudio-Nerbioi, “Arrigorriaga creará 16 nichos para el colectivo musulmán en Euskadi”, 20/07/2020, deia.es. Recuperado de: https://www.deia.eus/bizkaia/laudio-nerbioi/2020/07/20/arrigorriaga-creara-16-nichos- 
Badajoz, Francisco Javier Fragoso (Partido Popular), a la concesión de un espacio para el enterramiento islámico, inexistente en toda la región.

En el caso del cementerio de Torrero (Zaragoza), por su parte, que ya contaba desde 2013 con un acuerdo de colaboración municipal y cuya adecuación había sido reconocida como "buena práctica" por el Observatorio del Pluralismo Religioso en España, en agosto de 2020 salía a la luz la tensión entre la Comunidad Islámica de Zaragoza y el Ayuntamiento del Partido Popular, ante la negativa de este de acoger enterramientos de difuntos no empadronados en la ciudad y alrededores por "falta de espacio", algo con lo que el presidente de esta comunidad y representante de la UCIDE en Aragón, Fawaz Nahhas, mostró su más profundo desacuerdo. El argumento de la falta de espacio en el contexto de la pandemia ha sido esgrimido en otras localidades como Fuengirola (Málaga), en cuyo cementerio islámico no fue permitido el enterramiento de una persona fallecida por covid-19 al estar empadronada en Melilla, un asunto que los medios locales de la Ciudad Autónoma no tardarían en hacerse eco ${ }^{4}$.

Entre otros casos de reivindicaciones desde que se inició el estado de emergencia sanitaria a los que hemos tenido acceso se encuentran el de Puertollano (Ciudad Real), donde en el mes de marzo Mohammed Kardali, presidente de la Asociación de Trabajadores Marroquíes (ATIM) en Castilla-La Mancha, solicitaba al Ayuntamiento "la cesión de una parcela" sin éxito por el momento. Sin embargo, esta acción airearía un episodio islamófobo local: en julio la Asociación Marroquí de Derechos de los Inmigrantes (AMDI) de Puertollano interponía ante la Fiscalía varias querellas por presuntos delitos de odio contra tres usuarios de Facebook que publicaron mensajes de incitación al odio contra la comunidad musulmana local. En Soria Ahmed El Boutaybi, presidente de la Comunidad Islámica de Soria, recordaba en el mes abril al Ayuntamiento de la ciudad que llevaba reclamando desde julio de 2015 contar con un espacio funerario islámico, una necesidad que "en situación de pandemia" era aún más acuciante. En Mallorca, Abderrahim Ouadrassi, presidente de la Fundación Euroafrica, denunciaba públicamente que "la mayoría de los migrantes africanos son musulmanes y deben ser enterrados por el rito islámico, pero en el cementerio de Mallorca no hay espacio y las fronteras están cerradas". También en el mes de abril, el presidente de la asociación Al-Yazira Al Khadra, Mohamed El Kammas el Moqadem de Algeciras (Cádiz) presentaba al Ayuntamiento una petición avalada por varios colectivos islámicos de la zona -como el Centro Islámico del Campo de Gibraltar (La Línea)- y de toda España, en la que volvía a solicitar, "esta vez de manera urgente, la cesión de una parcela en el cementerio municipal para enterramientos de musulmanes". Unas primeras actuaciones sin resultados precedieron a las mantenidas en el mes de noviembre entre nuevos interlocutores: por un lado, Juan Lozano, presidente de la Mancomunidad de Municipios del Campo de Gibraltar y la vicepresidenta Jessica Barea; y por otro, el mismo Mohamed El Kammas el Moqadem, pero esta vez como presidente de la Comunidad Islámica Al Rahma y miembro de la CIE, junto a Driss Mohamed, vicepresidente de esta comunidad y candidato a la Alcaldía de Algeciras por el partido PRUNE en las anteriores elecciones locales. Si bien esta reunión no se materializó en la construcción de un cementerio, supuso para esta institución "conocer de primera mano las necesidades e inquietudes de los colectivos, asociaciones y

\footnotetext{
${ }^{4}$ Véase: Alicia Martínez (2020): "Se le niega a un melillense ser enterrado en el cementerio musulmán de Fuengirola". 10/04/2020. elfarodemelilla.es. Recuperado de: https://elfarodemelilla.es/niega-melillense-enterrado-cementeriomusulman-fuengirola/
} 
comunidades existentes en el Campo de Gibraltar"5. Más al sur, en Ceuta el Movimiento por la Dignidad y la Ciudadanía (MDyC) volvía a hacer pública su demanda reiterada de la necesaria ampliación del cementerio musulmán de Sidi Embarek, y dos meses más tarde el Gobierno de la Ciudad Autónoma anunciaba las inmediatas obras para la ampliación, argumentando su concesión "por emergencia dada la situación tan crítica generada"6.

\section{Madrid, un caso "enquistado"}

El último cementerio islámico en la ciudad de Madrid del que se tiene constancia data del siglo IX, situado bajo la actual plaza de la Cebada en el barrio de La Latina, extendiéndose hacia el sur (GilBenumeya, 2016, 2018, 2020; Martínez Núñez, 2015; Murillo, 2009). Como apunta Gil-Benumeya, esta maqbara islámica "acogió el descanso eterno de los musulmanes madrileños hasta principios del XVI" (Gil-Benumeya, 2016: 35). Desde entonces no ha existido otro espacio funerario islámico, con la excepción del particular caso de un enterramiento en el cementerio británico de Carabanchel, construido para los británicos fallecidos en la ciudad, y que con el paso del tiempo llegaría a acoger difuntos de muchas otras nacionalidades. Esta diversidad está presente también en la adscripción religiosa de las personas enterradas, pues además de las tumbas de difuntos anglicanos, hay también de protestantes, ortodoxos y judíos, y la de una mujer musulmana enterrada en el año 1963 (Butler, 2020). Es la tumba de Aicha Tilmisani, que se encuentra en un pequeño espacio anexo al cementerio y separado del recinto por una puerta metálica y en cuya lápida puede leerse en árabe "No hay más divinidad que Dios, Muhammad es el mensajero de Dios. Tumba de la difunta Aicha Tilmisani, esposa de Muhammad Mayid Ali, 1937-1963".

Era una señora británica de origen marroquí, como su marido, que era marroquí y naturalizado inglés. (...) La embajada británica, como ella era ciudadana, tomó las riendas del asunto y le aconsejaron que podía enterrarse aquí a extramuros, por eso está enterrada fuera de la tapia, lo cual es una pena porque este es un cementerio multicultural (responsable del cementerio británico, Madrid, 2/06, 2021).

Así, con esta última excepción, desde la conversión de los últimos musulmanes al cristianismo en el siglo XVI, no se tiene constancia de más enterramientos islámicos en la capital, convirtiéndose dicha carencia en una importante necesidad comunitaria con el asentamiento de población migrante musulmana desde finales del pasado siglo. Una necesidad que, como ha quedado expuesto, se ha hecho aún más apremiante con la pandemia del covid-19. Ante esta situación, la Comunidad Musulmana Abu Madian - Tariqa Alawiya Gawziya (Ceuta), apoyada por un conjunto de entidades religiosas musulmanas y asociaciones culturales y sociales de distinta índole y procedentes de diferentes puntos de la geografía estatal (con las que -según la carta- habían "establecido una plataforma relativa a este tipo de demandas"), enviaron una carta al Ayuntamiento de Madrid el 13 de marzo de $2020^{7}$, solicitando sin éxito la habilitación de una parcela en el cementerio de Carabanchel para enterramientos musulmanes:

\footnotetext{
${ }^{5}$ Véase: Redacción (2020): “Juan Lozano y el PSOE trabajarán para la construcción de un cementerio musulmán en la comarca". 21/11/2020. horasur.com. Recuperado de: https://www.horasur.com/articulo/campo-de-gibraltar/juanlozano-psoe-comarcal-trabajaran-construccion-cementerio-musulman/20201121222531045396.html

6 Véase: Echarri, Carmen (2020): "Las obras para la ampliación del cementerio musulmán comienzan el lunes" 1/05/2020. elfarodeceuta.es. Recuperado de: https://elfarodeceuta.es/ampliacion-cementerio-musulman-comienzalunes/

${ }^{7}$ La carta fue enviada por la Comunidad Musulmana Abu Madian- Tariqa Alawiya Gawziya (Ceuta), y contó con el apoyo de: la Comunidad Islámica Mezquita Ishbilia (Sevilla), la Comunidad Islámica Al-Jazira al Khadra del Saladillo (Cádiz), la Comunidad Islámica Assalam de Segovia, el Centro Cultural Islámico Parque Amate (Sevilla), el Centro Islámico del
} 
Sin respuesta. Nos lo esperábamos, porque sabemos que no hay interés. Es decir, el islam para mucha gente es una molestia (...) Nos esperábamos eso, incluso si hubieran estado los socialistas en el Ayuntamiento, tampoco nos esperaríamos gran cosa. A lo mejor si estuviera Carmena sí. Carmena era otra cosa. Pero yo creo que ahora mismo no hace falta seguir insistiendo. Simplemente se trata de llevar el tema por otros cauces quizás (miembro de la Comunidad Abu Madian-Tariqa Alawiya Gawziya, Ceuta, 9/02/2021).

En esta misiva también se ponía de manifiesto el descontento de estas entidades y asociaciones con "las distintas federaciones, asociaciones y comunidades musulmanas" tanto del ámbito local como del estatal por no haber reivindicado suficientemente esta demanda ante las instituciones públicas. En este sentido, en la fecha en que fue enviada la carta no hay constancia de que la CIE se hubiese dirigido públicamente al Ayuntamiento para efectuar una solicitud al respecto. Para ello habría que esperar al 14 de diciembre de ese mismo año con la celebración de una reunión entre la CIE, encabezada por su nuevo presidente, Ayman Adlbi, el Ayuntamiento de Madrid y la Empresa Municipal de Servicios Funerarios ${ }^{8}$.

...lo último que he llegado a saber fue en noviembre del año pasado [2020] cuando hablé en persona con el nuevo presidente de la Comisión Islámica, el Dr. Ayman Idlibi, que él va a encargar del asunto con el Ayuntamiento (antiguo miembro del CCIM, Madrid, 14/03/2021).

Tanto la solicitud de la Tariqa ceutí, como las interlocuciones de la CIE y el Gobierno local, se apoyaban en un proyecto funerario, el de Carabanchel, que no sólo no era nuevo, sino que ha ido reivindicándose en diferentes momentos de las dos últimas décadas, tal y como se describe a continuación.

\section{Genealogía del proyecto del cementerio islámico de Carabanchel}

El distrito de Carabanchel, ubicado al sur de Madrid, alberga el Cementerio Sur, el segundo más grande de la ciudad después del de la Almudena. Junto a esta dotación municipal, Carabanchel cuenta con otros cinco cementerios de gran valor histórico-patrimonial, los denominados "sacramentales" - San Lorenzo y San José; Santa María; San Miguel, Santa Cruz, Santos Justo y Pastor y San Millán; y San Isidro, San Pedro, San Andrés y Ánimas Benditas; y el citado cementerio británico, que fue inaugurado en 1854 para dar sepultura a difuntos británicos que no fuesen católicos, si bien, desde prácticamente sus inicios en el mismo se enterrarían también personas de otras confesiones no católicas.

\footnotetext{
Campo de Gibraltar, la asociación Musulmanes contra la Islamofobia (Barcelona), la Asociación Musulmana por los Derechos Humanos (Madrid) y la Asociación Ceutí para el Diálogo Intercultural (ACEDI).

${ }^{8}$ A esta reunión asistieron, por parte de las instituciones públicas, Ivo Villalba Pozo, Director del Gabinete del Área de Gobierno de Portavoz, Seguridad y Emergencias; Fernando Sánchez González, Gerente de la Empresa Municipal de Servicios Funerarios y Cementerios de Madrid y, por parte de la CIE, su actual presidente, Aiman Adlbi; el secretario, Mohamed Ajana Elouafi; el delegado de la Comisión en Madrid, Mustafa Abdeselam, y un miembro de la comisión de mezquitas y cementerios, Mohamed Kharchiche.
} 
En este contexto, la ubicación urbana, la disponibilidad de terreno y la lejanía por el momento de su colmatación, hacían del Cementerio Sur de Carabanchel un espacio idóneo para plantear la habilitación de una parcela islámica; del mismo modo que, durante el reinado de Alfonso XII en 1922, se había hecho en el Cementerio de la Almudena con la construcción del Cementerio Municipal Hebreo, actualmente en activo. Y así lo comprendieron los responsables de la primera solicitud de la que tenemos constancia: en el año 2000 el Centro Cultural Islámico de Madrid (CCIM), conocido como la "mezquita de la M-30", se dirigía al Ayuntamiento de la capital en este sentido. Esta institución cultural ya había reclamado en 1995 al Ayuntamiento la habilitación de un tanatorio en su propio centro; reclamación que fue denegada por no cumplir con los requisitos de la normativa vigente. La solicitud del cementerio no correría mejor suerte, siendo rechazada en primera instancia por el Departamento de Patrimonio de la Gerencia y Urbanismo, alegando que no se disponía del suelo municipal de la superficie y compatibilidad de uso solicitado. Meses después, la Dirección de Servicios del Plan General de la Gerencia y Urbanismo hacía público un informe que planteaba tres alternativas diferentes, una de las cuales parecía satisfacer a todas las partes, la cesión de una parcela municipal; sin embargo, finalmente el proyecto no conseguiría llegar a término.

En 2004 el CCIM vuelve a dirigirse al Gobierno municipal. En el mes de septiembre se celebran varias reuniones entre el Centro y el Área de Gobierno de Seguridad y Servicios a la Comunidad, iniciándose los trámites para elaborar un convenio. En los meses siguientes el Ayuntamiento recaba los respectivos informes de los departamentos de Salud Pública, Urbanismo y de la Empresa Mixta de Servicios Funerarios para la redacción de un borrador. En octubre del 2005 el Ayuntamiento fija la fecha de la firma del convenio el 7 de noviembre del mismo año. Sin embargo, el CCIM reclamaría un aplazamiento de la firma por su coincidencia con el mes del Ramadán. La solicitud de aplazamiento fue aceptada por el Consistorio, fijándose la nueva fecha para el 14 de enero de 2006. Poco después el representante del CCIM solicitaría una reunión previa a la fecha señalada para hacer una serie de puntualizaciones sobre el borrador del convenio. Aunque el Ayuntamiento accede, el CCIM terminaría por cancelar la reunión el mismo día de su celebración, el 10 de enero. Fuentes consultadas a este respecto nos cuentan que el acuerdo no llegaría finalmente a firmarse porque la $\mathrm{CIE}$ reclamó sus competencias en la materia como interlocutor legítimo con los poderes públicos:

...había un plan hecho y completo de un cementerio musulmán en Carabanchel en Madrid desde 2006 que se quedó al final en los cajones (...) el tema tiene una relación entre el Ayuntamiento de Madrid y la Comisión Islámica de España, y había un conflicto de intereses y por ello en 2007 el Centro Cultural Islámico de Madrid dejó de ocuparse del tema (antiguo miembro del CCIM, Madrid, 14/03/2021).

A la espera de una respuesta del CCIM, el concejal de Seguridad y Servicios a la Comunidad, Pedro Calvo del Partido Popular, anuncia en el Pleno del 28 de febrero de 2006 la cesión de una parcela del Cementerio Sur de Carabanchel de 10.000 metros cuadrados de extensión y con cerramientos y accesos independientes, para la inhumación de cuerpos de acuerdo con los rituales islámicos. Al mismo tiempo, señala que la conservación, mantenimiento y vigilancia del lugar será responsabilidad de la propia comunidad islámica. Este anuncio se produce durante el turno de réplica a una proposición presentada por el Grupo Municipal Socialista, en la que, el concejal Ramón Silva Buenadicha, solicitaba al Gobierno local que llegase a un acuerdo con la CIE para habilitar una parcela en la que poder realizar enterramientos islámicos. Según señalará más tarde en el Pleno el propio concejal socialista, los preparativos de firma del convenio que había llevado a cabo el Ayuntamiento eran desconocidos no sólo por su grupo municipal, sino también por "una parte de la comunidad musulmana". Concretamente se refería, por un lado, a la UCIDE, cuyo secretario general, Helal-Jamal Aboshi, asistiría a dicho Pleno; y, por otro, a la que, en sus propias palabras, fue la "inspiradora de la proposición", la Fundación de Cultura Islámica (FUNCI), la cual, sin embargo, es 
una institución española sin ánimo de lucro, apolítica, aconfesional y científica y, por tanto, no una entidad islámica que forme parte de la "comunidad musulmana".

En estos términos quedaba patente la confusión existente en torno al representante legítimo de la comunidad islámica para actuar como interlocutor público, el entonces alcalde del Partido Popular, Alberto Ruiz Gallardón, propone solicitar información al Ministerio de Asuntos Exteriores. Nuevamente, el proyecto del cementerio musulmán vuelve a quedar en suspenso.

[desde $\mathrm{FUNCl}$ ] se intentó ver cómo estaba el tema del cementerio musulmán en Madrid y ver las posibilidades que había... por su cuenta y riesgo, de las posibilidades que había de crear un cementerio islámico en Madrid. (...) Se habló con el PSOE, que se comprometió a Ilevarlo a un Pleno del Ayuntamiento (...) Después también se trató el tema con Tatary, que parece que al principio no se mostró muy interesado en el asunto, aunque luego sí, y una representación de la UCIDE se personó en aquel Pleno (miembro de $\mathrm{FUNCl}$, Madrid, 8/04/2021).

En el fracaso del proyecto intervinieron varios factores. Tal como valoraba el concejal socialista Silva Buenadicha, durante una entrevista realizada para la redacción de este artículo, las diferencias internas entre las distintas comunidades musulmanas no habían beneficiado en absoluto; pero tampoco el Ayuntamiento ni la Empresa Mixta de Servicios Funerarios habían mostrado excesivo interés en la cesión de la parcela municipal, quienes, en lugar de una cesión, propusieron la venta de una parcela del cementerio de Carabanchel. Este afán de lucro era más evidente en la Empresa Mixta, semiprivatizada desde 1993 con la venta del 49\% de las acciones de la hasta entonces empresa pública por el Gobierno del alcalde popular Álvarez del Manzano, que obtenía gran parte de los beneficios por la comercialización de las sepulturas.

...la comercialización de las sepulturas de los cementerios era beneficio para la Empresa Mixta y, al final, esos beneficios se repartían con el Ayuntamiento, pero quien más ganaba era la Empresa Mixta. Si se vendía la parcela, quien iba a beneficiarse era esa Empresa Mixta, porque formaba parte del cementerio. Si hubiese sido una parcela municipal en otro sitio, pues el beneficiario hubiese sido el Ayuntamiento, pero al ser parte del cementerio... Además, la Empresa Mixta no dejaba pasar ni una (concejal municipal por el Grupo Socialista, Madrid, 18/04/2021).

De esta forma, el proyecto del cementerio musulmán pasaba a un segundo plano desde el momento en el que se negociaba la cesión y no la venta de la parcela; y si bien el proyecto de cesión fue presentado en el Pleno, no fue por iniciativa propia del concejal popular, sino a raíz de una pregunta formulada por su homónimo socialista tras los citados primeros encuentros con la FUNCl.

Una década después, en 2016, el cementerio musulmán de Carabanchel reaparece en la palestra pública, de forma coetánea al de Griñón, el cual ya llevaba dos años en el "ojo del huracán" tras su cierre temporal decretado por el Ayuntamiento de esta localidad en noviembre de 2014 con el fin de regularizar su situación de acuerdo con el Decreto 124/1997, de 9 de octubre, que aprueba el Reglamento de Sanidad Mortuoria, norma que no había sido anteriormente atendida por el Consulado de Marruecos desde que asumió su gestión en los años setenta. Las protestas ciudadanas no tardarían en llegar, como la del 22 de noviembre frente al Ministerio de Justicia convocada por 
media docena de asociaciones, como la Asociación de Jóvenes Musulmanes de España (AJME) que en uno de sus comunicados en la red social Facebook, alertaba sobre "la pasividad e inoperancia de nuestros representantes oficiales, la intransigencia de las instituciones públicas y la vulneración de los derechos fundamentales de la comunidad musulmana". Con ello, estas protestas se repetirían durante algún tiempo, también después de la reapertura, pues tanto la obligatoriedad del féretro, como el encarecimiento del coste de los enterramientos con las nuevas tarifas, no serían del agrado de la heterogeneidad de los colectivos islámicos ${ }^{9}$.

En este contexto marcado por la polémica, el Ayuntamiento de Madrid recupera la propuesta del cementerio de Carabanchel. Mientras la CIE había estado implicada en las negociaciones con el cabildo griñonense, había empezado también a mantener relaciones con el nuevo equipo de Gobierno local, regentado por Manuela Carmena de Ahora Madrid. Fruto de estas conversaciones, la alcaldesa anunciaba el 15 de marzo de 2016 su intención de reservar una parcela de 10.000 metros cuadrados para la población musulmana en el Cementerio de Carabanchel Alto, aunque aclaraba que, por el momento tanto en Madrid como en su homónimo de Griñón, los enterramientos continuarían realizándose en féretro ${ }^{10}$.

...me ha gustado incluso el lenguaje de los responsables del Ayuntamiento en el sentido de que entienden la diversidad religiosa o cultural que hay en el municipio de Madrid y se adaptan a las normas; y la norma dice que los vecinos musulmanes deben tener un cementerio. Por lo menos desde parte del ayuntamiento se está haciendo un esfuerzo para que los musulmanes tengamos un cementerio, esta parte está bastante avanzada (...) se está haciendo ahora [2016] un informe un estudio, pero en paralelo se debe esperar lo que se llama el informe correspondiente de la Consejería de Sanidad (secretario de la CIE, Madrid, 25/10/2016).

Por su parte, Javier Barbero, entonces concejal delegado del Área de Salud, Seguridad y Emergencias, señalaba que la operación se acometería cuando la Empresa Mixta de Servicios Funerarios volviese a manos del Ayuntamiento ${ }^{11}$, a la vez que destacaba el "esfuerzo" de las comunidades islámicas por buscar "una manera de asimilarse a la ley" y poder cumplir al tiempo con sus ritos de enterramiento. En este orden, pese a las peticiones de la comunidad islámica para la cesión de una parcela, el Ayuntamiento finalmente se decanta por la modalidad de préstamo; y se compromete a negociar con la Comunidad de Madrid, en manos del Partido Popular y presidido en ese momento por Cristina Cifuentes, la modificación del reglamento para permitir la inhumación sin féretro, tal y como se había hecho ya en otras Comunidades Autónomas como Andalucía o Valencia.

\footnotetext{
${ }^{9}$ Un caso que guarda algunas similitudes con el del cementerio de Griñón es el de Logroño (La Rioja). En 2017 distintas organizaciones vecinales y sociales y comunidades religiosas reclamarían al Ayuntamiento de la ciudad el reacondicionamiento y la ampliación del cementerio islámico, unas obras que, sin embargo, no empezarían a acometerse hasta el mes de abril de 2021. Como sucedió en Griñón, en Logroño el proceso de reivindicación también estuvo protagonizado por una diversidad de actores, no sólo políticos e institucionales, sino también musulmanes, como, por ejemplo, por un lado, una red de organizaciones como la Asociación de Trabajadores Inmigrantes Marroquíes (ATIM) y la Asociación Pakistaní de La Rioja, quienes en 2008 habían ya creado una coalición para reclamar el actual cementerio que se inauguraría en diciembre de 2009; y, por otro, el de la CIE, cuya delegación en La Rioja sería finalmente a inicios del 2021 el interlocutor islámico ante el cabildo logroñés para tratar la insuficiencia de espacio.

10 Junto a este anuncio, el Ayuntamiento hacía pública también la destinación por vez primera en la historia local de una partida de 150.000 euros en los presupuestos municipales de 2016 para festejar el Ramadán, a través de programas culturales y eventos en el marco de Las noches de Ramadán. Un ciclo en el que, hasta entonces, Casa Árabe (Ministerio de Asuntos Exteriores) había sido la única institución pública encargada de organizar todas las actividades culturales relacionadas con el mundo musulmán en Madrid.

${ }^{11}$ La cual sería remunicipalizada por el Ayuntamiento de Madrid (Ahora Madrid) en septiembre de 2016, pasando a denominarse Empresa Municipal de Servicios Funerarios y Cementerios de Madrid, S.A.
} 
El tema del diálogo o las vías de resolución yo creo que tal como están marcadas están bastante bien, lo que hace falta es que a la hora de llevarlo a la práctica no nos mareen, nada más, porque a veces cuando vas al Ayuntamiento de Madrid o a la Comunidad Autónoma, te dicen, 'el Ministerio de Justicia hace esas normas' y entonces el funcionario de turno empieza a hacer un esfuerzo de interpretación que a veces dependiendo del partido político, depende de la experiencia personal de cada uno te puede facilitar las cosas o te las puede complicar (secretario de la CIE, Madrid, 25/10/2016).

Mientras que se esperaba la implementación de esta medida, el Ayuntamiento daba un paso más con el Plan de Derechos Humanos del Ayuntamiento de Madrid (2017-2020), que de un total de 28 "metas", la número 3 estaba dedicada al Derecho a la libertad de conciencia, religión, opinión e información. Las propias confesiones vecinas de la ciudad (con la CIE como representación islámica), en un taller para la confección del Plan presentaban un diagnóstico con 13 puntos, seis de los cuales se relacionaban con el espacio: dos sobre lugares de culto ${ }^{12}$, tres sobre el espacio y los equipamientos públicos ${ }^{13}$; y uno sobre cementerios y servicios funerarios relativo a las carencias de espacio y en la adecuación de las prácticas a las prescripciones religiosas.

Sin embargo, ni los nuevos números exitosos de la empresa pública, ni los efectos de una gestión pública local sensible a la diversidad, serían capaces de acometer el proyecto del cementerio musulmán en Carabanchel. Las elecciones de junio de 2019 traerían consigo el relevo consistorial y, con ello, la suspensión, nuevamente, del ansiado proyecto hasta su nueva reivindicación con los devastadores efectos de la pandemia del covid-19.

\section{Conclusiones}

Casi treinta años después de que se reconociese el derecho de las personas musulmanas a recibir sepultura de forma acorde a sus prescripciones religiosas, resulta significativo que en muchas localidades españolas en las que existe una comunidad musulmana plenamente consolidada, no se disponga todavía de un espacio funerario para ello. Más si cabe cuando la reivindicación relativa a la cuestión funeraria se ha convertido en la principal demanda realizada por las comunidades musulmanas a las instituciones públicas.

Como se ha puesto de manifiesto a lo largo del presente artículo, la ciudad de Madrid es una de estas localidades, en la que, a pesar de las múltiples reivindicaciones de las comunidades musulmanas y de los proyectos elaborados por distintos gobiernos locales, aún no cuenta con un cementerio musulmán. Esta situación, que ya comportaba gravedad con anterioridad, ha cobrado mayor relevancia durante los meses de la pandemia del covid-19 a consecuencia del incremento del

\footnotetext{
12 Dificultades para la obtención de las licencias de apertura y aplicación de regímenes propios de otros locales como bares y discotecas.

${ }^{13}$ Ausencia del factor y de los actores religiosos en los debates en torno al espacio público; dificultades en su acceso por una gestión funcionarial marcada por el desconocimiento legal y sociológico; y establecimiento de tasas por el uso del espacio público, a veces desorbitadas, que impiden el acceso al mismo a los colectivos y comunidades con menos recursos.
} 
número de fallecimientos. Ante esta situación diversas entidades religiosas musulmanas y asociaciones sociales y culturales solicitaron al Ayuntamiento de Madrid una parcela musulmana en el cementerio de Carabanchel. Esta reivindicación al margen de la CIE en tanto designado por el Gobierno órgano interlocutor oficial de las comunidades musulmanas en España con los poderes públicos no ha sido una excepción del periodo de la pandemia; pues desde que en 1992 se reconociese el derecho de las personas musulmanas a recibir un enterramiento de acuerdo con sus prescripciones religiosas, algunas de las reivindicaciones efectuadas en este sentido han sido protagonizadas por otros actores religiosos, y también civiles, como resultado de la sinergia principalmente de tres factores: la relevancia de la cuestión funeraria en tanto hecho social total; el papel muchas veces obstructivo de los poderes públicos implicados; y la propia heterogeneidad de actores, intereses, discursos y prácticas que alberga esta umma estatal.

Esta heterogeneidad de actores, además, puede traer consigo algunas dificultades relacionadas con la representatividad y la legitimidad de la $\mathrm{CIE}$, un órgano creado para la interlocución con el Estado en todos sus niveles territoriales y competenciales, pero que, pese a sus esfuerzos en este sentido, no siempre es legitimada por el grueso de los integrantes de la heterogénea comunidad musulmana siendo capaz de aglutinar los diversos intereses de la misma. Un potencial y latente conflicto de intereses que no es exclusivo de los colectivos islámicos de este país, sino más bien propio de las sociedades complejas y democráticas en las que el disenso y el conflicto son más habituales que el propio acuerdo.

La recepción por parte de los poderes públicos de las diferentes reivindicaciones también ha sido diversa. La descentralización de las competencias obliga a las comunidades musulmanas a negociar con cada municipio, de manera que el éxito o el fracaso de las reivindicaciones se ve, a su vez, condicionado por múltiples factores, entre los que se encuentra la receptividad de cada ayuntamiento a las cuestiones religiosas. Entre los gobiernos locales tratados, el que mayor interés ha mostrado ha sido el liderado por Manuela Carmena, ya que en él no solamente se proyectó la habilitación de una parcela en el cementerio municipal de Carabanchel, sino que además se implementó una política local que ponía el acento en la diversidad, con medidas como el Plan de Derechos Humanos o la aprobación de una partida presupuestaria para festejar el Ramadán.

Sin embargo, para entender el fracaso de todos los proyectos de un cementerio musulmán en la ciudad de Madrid hay que tomar en consideración, además de la mayor o menor voluntad política de cada uno de los gobiernos, otros factores como el económico, que explica el obstáculo que supuso la Empresa Mixta en la firma de un plan elaborado durante el mandato de Alberto RuizGallardón. Al mismo tiempo, no podemos olvidar que la cuestión funeraria, entendida como un hecho social total, implica un conjunto de ámbitos como son el religioso, el moral, el político y el jurídico. En este último se incluye el derecho que adquirieron las personas musulmanas a recibir un enterramiento de acuerdo con su ritual funerario y que representa también un "derecho a la ciudad" en la medida en que la ciudadanía se ejerce recuperando el espacio público que le es negado. Solo cuando se cuente con un cementerio musulmán en la ciudad de Madrid, la heterogénea comunidad musulmana local podrá ver reconocida esta parte de su ciudadanía que hasta el momento tiene negada.

\section{Bibliografía}

AJANA ELOUAFI, Mohamed (2020): Informe sobre los cementerios para los musulmanes, a fecha de 10 de abril de 2020, Madrid, Comisión Islámica de España. 
Ó. Salguero y A. Siguero, La cuestión funeraria islámica: el "enquistado" caso...

ALONSO, Marta; GHALI, Khalid; LÓPEZ-BARGADOS, Alberto; MORERAS, Jordi \& SOLÉ, Ariadna (2010): "Rituals islàmics en diáspora: Les comunitats musulmanes a Catalunya", Revista d'etnologia de Catalunya, no 36, pp. 171-176.

ANSARI, Humayun (2007): "'Burying the dead': making Muslim space in Britain", Historical Research, vol. 80, no 210, pp. 546-566. DOI: 10.1111/j.1468-2281.2007.00432.x

ARAMBURU, Mikel (2008): “Usos y significados del espacio público", ACE: Arquitectura, Ciudad y Entorno, vol. 3, no 8, pp. 143-149. DOI: 10.5821/acev3i8.2461

ASTOR, Avi y GRIERA, Mar (2016): "La gestión de la diversidad religiosa en la España contemporánea", Anuario CIDOB de la Inmigración, no 1, pp. 248-70. DOI: 10.24241/AnuarioCIDOBInmi.2016.248

BUTLER, David J. (2020): Absent Friends, Madrid, Círculo Rojo.

CAZENEUVE, Jean (1970): Sociología de Marcel Mauss, Barcelona, Ediciones Península.

DELGADO, Manuel (2013): “El espacio público como representación. Espacio urbano y espacio social en Henri Lefebvre", en Jornadas A Cidade Resgatada, Ordem dos Arquitectos - Seção Regional Norte, Oporto (Portugal), mayo.

FERNÁNDEZ, Daniel A. (2018): “Islamofobia queerizada y resistencias musulmanas queer en tiempos de homonacionalismo", Revista de Estudios Internacionales Mediterráneos, no 24, pp. 71-88. DOI: 10.15366/reim2018.24.005

GIL-BENUMEYA, Daniel (2016): “El cementerio musulmán de Madrid: la maqbara olvidada", Madrid Histórico, no 65, pp. 35-39.

GIL-BENUMEYA, Daniel (2018): Madrid islámico. La historia recuperada, Madrid, Madrid Destino Cultura Turismo y Negocio, S.A.

GIL-BENUMEYA, Daniel (2020): “Ritos funerarios islámicos en Madrid, de ayer a hoy”, en CARRIÓN, Elena (ed.): La Maqbara de Maŷrīț. La muerte en el Madrid islámico, Madrid, Comunidad de Madrid, pp. 77-86.

HUDSON, Wayne (2003): "Religious Citizenship", Australian Journal of Politics and History, vol. 49, no 3, pp. 425-429. DOI: 10.1111/1467-8497.00296

KLAPETEK, Martin (2017): "Muslim Areas at Municipal Cemeteries in Germany and Austria", Studia Religiologica, vol. 50, no 3, pp. 203-220. DOI: 10.4467/20844077SR.17.013.7746

KLAUSEN, Jytte (2007): The Islamic Challenge: Politics and Religion in Western Europe, Oxford, Oxford Scholarship Online. DOI: 10.1093/acprof:oso/9780199231980.001.0001

KRAUSE, Kristine y SCHRAMM, Katharina (2011): "Thinking through Political Subjectivity", African Diaspora, no 4, pp. 115-134. DOI: 10.1163/187254611X607741

LEFEBVRE, Henri (1968): Le Droit à la ville, París, Anthropos.

LEFEBVRE, Henri (1974): La production de l'espace, París, Anthropos.

LEMS, Johanna M. (2021): Analizando nuevas subjetividades políticas. Comunidades musulmanas en la esfera pública española (Tesis doctoral), Repositorio Institucional de la Universidad Complutense de Madrid, https://eprints.ucm.es/id/eprint/67059/. 
LÉVI-STRAUSS, Claude (1979): “Introducción a la obra de Marcel Mauss", en MAUSS, Marcel (dir.): Sociología y antropología, Madrid, Tecnos, pp. 13-42 (1a ed. 1923-24).

MARTÍNEZ NÚÑEZ, Ma Antonia (2015): “Estela funeraria de cronología omeya aparecida en Madrid (308/921)", Al-Qantara, vol. XXXVI, no 1, pp. 141-163.

MAUSS, Marcel (1979): Sociología y antropología, Madrid, Tecnos (1a ed. 1923-24).

MAUSSEN, Marcel (2007): "The governance of Islam in Western Europe. A state of the art report", IMISCOE Working Paper, no 16.

MORERAS, Jordi (2004): “Morir lejos de casa: la muerte en contexto migratorio”, en LÓPEZ, Bernabé y BERRIANE, Mohamed (dirs.): Atlas 2004 de la inmigración marroquí en España, Madrid, Taller de Estudios Internacionales Mediterráneos de la UAM, pp. 427-430.

MORERAS, Jordi (2017): “¿Qué islam para qué Europa? Hacia una antropología del islam posmigratorio en Europa", Revista CIDOB d'Afers Internacionals, № 115, pp. 13-37. DOI: 10.24241/rcai.2017.115.1.13

MURILLO, Jose I. (2009): "Registro estratigráfico de una necrópolis musulmana en la calle Toledo, 68 (Madrid). El proceso de islamización a través del ritual de enterramiento", en BENET, Nicolás (coord.): Actas de las terceras jornadas de Patrimonio Arqueológico en la Comunidad de Madrid, Madrid, Comunidad de Madrid, Dirección General de Patrimonio Histórico, pp. 89-98.

OBSERVATORIO ANDALUSí (2020): Estudio demográfico de la población musulmana. Explotación estadística del censo de ciudadanos musulmanes en España referido a fecha 31/12/2019, Madrid, Unión de Comunidades Islámicas de España.

VAN DEN BREEMER, Rosemarie y MAUSSEN, Marcel (2012): "On the Viability of State-Church Models: Muslim Burial and Mosque Building in France and the Netherlands", Journal of Immigrant \& Refugee Studies, vol. 10, no3, pp. 279-298, DOI: 10.1080/15562948.2012.693037

SALGUERO, Óscar y HEJAZI, Hutan (2020): “El islam en el espacio público madrileño”, Disparidades. Revista de Antropología, vol. 75, no 1, e011, disponible en http://dra.revistas.csic.es/index.php/dra/article/view/753 [consulta: 16 de junio de 2021]. DOI: 10.3989/dra.2020.011

SALGUERO, Óscar (2011): “El cementerio islámico de Granada. Sobre los procesos de recuperación del espacio público por la comunidad musulmana local", Bandue. Revista de la Sociedad Española de Ciencias de las Religiones, no V, pp. 201-228.

SALGUERO, Óscar (2013): Espacio público y privado en el contexto del pluralismo religioso: minorías religiosas en Granada y su Área Metropolitana (Tesis doctoral), Granada, Universidad de Granada.

SALGUERO, Óscar (2020): "El islam en el espacio público de los barrios multiculturales del sur de Europa: el caso de Lavapiés, Madrid", Revista de Humanidades, no 41, pp. 181-203. DOI: 10.5944/rdh.41.2020.27939

SHAW, Alison (2004): "Immigrant Families in the UK", en SCOTT, Jacqueline; TREAS, Judith y RICHARDS, Martin (eds.): The Blackwell Companion to the Sociology of Families, Oxford, Blackwell Publishing Ltd., pp. 270-285.

TARRÉS, Sol y MORERAS, Jordi (2019): "La muerte reservada. Discusión (de nuevo) sobre la separación entre tumbas", en MORERAS, Jordi (coord.): Socio-antropología de la muerte: Nuevos enfoques en el estudio de la muerte, Tarragona: Publicacions de la Universitat Rovira i Virgili, pp. 171-198.

TARRÉS, Sol y SALGUERO, Óscar (2010): “Musulmanes en Andalucía”, en BRIONES, Rafael (dir.): Y tú (de) quién eres. Minorías religiosas en Andalucía, Barcelona, Icaria, pp. 289-347. 
Ó. Salguero y A. Siguero, La cuestión funeraria islámica: el "enquistado" caso...

TARRÉS, Sol (2006): “Ritos funerarios en el islam. La praxis entre los musulmanes de Sevilla”, Zainak. Cuadernos de Antropología-Etnografía, no 28, pp. 429-446.

TÉLLEZ, Virtudes (2018): “El ‘Pacto Antiyihadista' y las estrategias de lucha contra la 'radicalización violenta'. Implicaciones jurídicas, políticas y sociales, Revista de Estudios Internacionales Mediterráneos, no 24, pp. 9-30. DOI: 10.15366/reim2018.24.002

THIEBAUT, Carlos (1998): Vindicación del ciudadano, Barcelona, Paidós.

URAL, Nur Y. (2014): "A Genealogy of Muslims Dying in France. Strasbourg Cemetery as a Contested Space", Sociology of Islam, vol. 2, no 1-2, pp. 1-20. DOI: 10.1163/22131418-00201006

VAGGIONE, Juan M. (2017): “La Iglesia Católica frente a la política sexual: la configuración de una ciudadanía religiosa”, Cadernos Pagu, № 50, disponible en https://www.scielo.br/i/cpa/a/tG3Vwp9BqY7kGGTS6WSJ7Zw/abstract/?lang=es [consulta: 16 de junio de 2021]. DOI: 10.1590/18094449201700500002

YUVAL-DAVIS, Nira (2006): "Belonging and the Politics of Belonging", Patterns of Prejudice, vol. 40, no 3, pp. 197-214. DOI: 10.1080/00313220600769331 